\title{
,ancis \\ CO Oxidation Capabilities of La- and Nd-Based Perovskites
}

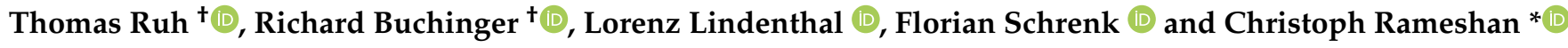 \\ Institute of Materials Chemistry, TU Wien, 1060 Vienna, Austria; thomas.ruh@tuwien.ac.at (T.R.); \\ e11706003@student.tuwien.ac.at (R.B.); lorenz.lindenthal@tuwien.ac.at (L.L.); florian.schrenk@tuwien.ac.at (F.S.) \\ * Correspondence: christoph.rameshan@tuwien.ac.at; Tel.: +43-1-58801-165115 \\ + These authors contributed equally to this work.
}

check for

updates

Citation: Ruh, T.; Buchinger, R.; Lindenthal, L.; Schrenk, F.; Rameshan, C. CO Oxidation Capabilities of La- and Nd-Based Perovskites. Fuels 2022, 3, 31-43. https://doi.org/10.3390/ fuels3010003

Academic Editor: Javier Ereña Loizaga

Received: 2 October 2021 Accepted: 10 December 2021 Published: 5 January 2022

Publisher's Note: MDPI stays neutral with regard to jurisdictional claims in published maps and institutional affiliations.

Copyright: (C) 2022 by the authors. Licensee MDPI, Basel, Switzerland. This article is an open access article distributed under the terms and conditions of the Creative Commons Attribution (CC BY) license (https:// creativecommons.org/licenses/by/ $4.0 /)$.

\begin{abstract}
Catalytic tests to assess the performance of mixed perovskite-type oxides $\left(\mathrm{La}_{0.9} \mathrm{Ca}_{0.1} \mathrm{FeO}_{3-\delta}\right.$ $\mathrm{La}_{0.6} \mathrm{Ca}_{0.4} \mathrm{FeO}_{3-\delta}, \mathrm{Nd}_{0.9} \mathrm{Ca}_{0.1} \mathrm{FeO}_{3-\delta}, \mathrm{Nd}_{0.6} \mathrm{Ca}_{0.4} \mathrm{FeO}_{3-\delta}, \mathrm{Nd}_{0.6} \mathrm{Ca}_{0.4} \mathrm{Fe}_{0.9} \mathrm{Co}_{0.1} \mathrm{O}_{3-\delta}, \mathrm{Nd}_{0.6} \mathrm{Ca}_{0.4} \mathrm{Fe}_{0.97}$ $\mathrm{Ni}_{0.03} \mathrm{O}_{3-\delta}$, and LSF) with respect to $\mathrm{CO}$ oxidation are presented as well as characterization of the materials by XRD and SEM. Perovskites are a highly versatile class of materials due to their flexible composition and their ability to incorporate dopants easily. CO oxidation is a widely used "probe reaction" for heterogeneous catalysts. In this study, it is demonstrated how tuning the composition of the catalyst material (choice of A-site cation, A-site and B-site doping) greatly influences the activity. Changing the A-site cation to $\mathrm{Nd}^{3+}$ or increasing the concentration of $\mathrm{Ca}^{2+}$ as A-site dopant improves the performance of the catalyst. Additional B-site doping (e.g., Co) affects the performance as well-in the case of Co-doping by shifting ignition temperature to lower temperatures. Thus, perovskites offer an interesting approach to intelligent catalyst design and tuning the specific properties towards desired applications.
\end{abstract}

Keywords: $\mathrm{CO}$ oxidation; rare earth perovskites; heterogeneous catalysis; catalyst design

\section{Introduction}

Oxide-type perovskites are a material class composed of two cations $\mathrm{A}$ and $\mathrm{B}$ (with the general formula $\mathrm{ABO}_{3}$ ), where $\mathrm{A}$ is larger than $\mathrm{B}$. Because of these fairly general criteria, perovskites are extremely versatile materials-provided the size ratio of $\mathrm{A}$ and $\mathrm{B}$ obey the well-known Goldschmidt stability factor [1], almost all elements across the periodic table can be used to make up the basic structure. Additionally, doping-both on A- and B-sites-is relatively easy and allows systematic tuning of the properties towards a given application [2,3]. Because of this compositional flexibility and their varied properties, perovskites are already used in a wide range of applications, for example in catalysis, fuel cells, or solid-state electrochemistry [4-10]. Properties that make perovskites interesting materials for use in industrial settings are in particular their thermal stability (and, consequently, the possibility to use them at high operating temperatures) as well as their resistance against catalyst poisons in connection with their regeneration capabilities via redox cycling.

In the last decades, La-based perovskites have been a topic of interest in catalyst research in biofuel production. For example, studies report utilization of $\mathrm{LaMeO}_{3}$ $(\mathrm{Me}=\mathrm{Sr}, \mathrm{Fe}, \mathrm{Co})$ in Fischer-Tropsch syntheses as support for $\mathrm{CoO}$ clusters [11] or directly as catalysts [12-14]. Similar La-based materials have also been used in catalytic synthesis of alcohols $[15,16]$, and $\mathrm{Cu}$-doped titanates have been recently investigated as catalysts for $\mathrm{CO}_{2}$ hydrogenation via computer simulations [17].

$\mathrm{CO}$ oxidation is widely used as a-seemingly — simple test reaction to assess catalytic performance of heterogeneous catalysts, especially for other oxidation processes [18]. Perovskites as catalysts for $\mathrm{CO}$ oxidation were mentioned 50 years ago as alternatives to precious metal catalysts in three-way catalysts, serving as an example of a technological application of CO oxidation $[19,20]$. Since then, extensive research into a broad range of different perovskite oxides has been done [21-24], studying their catalytic activity, stability, 
and properties both doped and undoped. Recently, La-based perovskites have been a main focus; for instance, $\mathrm{LaCoO}_{3}$ and $\mathrm{LaMnO}_{3}$ (and derived catalysts) have been investigated intensively for their utilization in $\mathrm{CO}$ oxidation [25-27], showing doping to be generally beneficial.

In this study, the previous work (see above) on La-based perovskites is extended by a series of seven doped $\mathrm{LnFeO}_{3}$-based $(\mathrm{Ln}=\mathrm{La}, \mathrm{Nd})$ perovskites that have not been investigated in this detail before. The perovskites were tested as catalysts in $\mathrm{CO}$ oxidation experiments in order to study the effect of different doping on their catalytic performance. The results were interpreted with respect to different possible reaction mechanisms (see Section 4 for more details). All materials were A-site doped with two different Ca contents ( $10 \%$ and $40 \% \mathrm{Ca}$, respectively), while the B-site was either undoped or doped with Co or Ni. Five of the investigated materials- $\mathrm{La}_{0.6} \mathrm{Ca}_{0.4} \mathrm{FeO}_{3-\delta}(\mathrm{La06}), \mathrm{La}_{0.9} \mathrm{Ca}_{0.1} \mathrm{FeO}_{3-\delta}(\mathrm{La} 09)$, $\mathrm{Nd}_{0.6} \mathrm{Ca}_{0.4} \mathrm{FeO}_{3-\delta}(\mathrm{Nd} 06), \mathrm{Nd}_{0.9} \mathrm{Ca}_{0.1} \mathrm{FeO}_{3-\delta}(\mathrm{Nd} 09)$, and $\mathrm{Nd}_{0.6} \mathrm{Ca}_{0.4} \mathrm{Fe}_{0.9} \mathrm{Co}_{0.1} \mathrm{O}_{3-\delta}(\mathrm{NdCo})-$ have been thoroughly characterized and used as catalysts for different types of reactions in previous studies $[2,3,28,29]$, while a new $\mathrm{Ni}$-doped catalysts $-\mathrm{Nd}_{0.6} \mathrm{Ca}_{0.4} \mathrm{Fe}_{0.97} \mathrm{Ni}_{0.03} \mathrm{O}_{3-\delta}$ $(\mathrm{NdNi}$ - with reduced B-site doping concentration has been synthesized additionally for this study. Commercial $\mathrm{La}_{0.6} \mathrm{Sr}_{0.4} \mathrm{FeO}_{3-\delta}$ (LSF) was used as reference material.

\section{Materials and Methods}

\subsection{Synthesis of Ni-Doped Perovskite}

All samples were prepared via the Pechini route [30]. In short, all precursors for the respective material are dissolved in doubly distilled water and $\mathrm{HNO}_{3}$ (doubly distilled, $65 \%$, Merck, Darmstadt, Germany). The following precursors were used for the preparation of the newly made material: $\mathrm{Nd}_{2} \mathrm{O}_{3}(99.9 \%$, Strategic Elements, Deggendorf, Germany), $\mathrm{CaCO}_{3}(99.95 \%$, Sigma-Aldrich, St. Louis, MO, USA), Fe (99.5\%, Sigma-Aldrich, St. Louis, $\mathrm{MO}, \mathrm{USA})$, and $\mathrm{Ni}\left(\mathrm{NO}_{3}\right)_{2} 6 \mathrm{H}_{2} \mathrm{O}(98 \%$, Sigma-Aldrich, St. Louis, MO, USA). Proper ratios of the solutions are then mixed in a quartz glass flask. To facilitate the formation of cation complexes citric acid (trace metal pure, $99.9998 \%$, Fluka, Honeywell International, Charlotte, NC, USA) is added in excess of $20 \%$. The solvents are evaporated off and the sponge-like intermediate is heated until self-ignition occurs, after which the material is calcined for $5 \mathrm{~h}$ at $800{ }^{\circ} \mathrm{C}$. The final product is then ground to a powder for subsequent experiments. Details on the synthesis can be found in Lindenthal et al. [3].

Since the initial characterization revealed the presence of an additional oxygen deficient phase, the newly synthesized material underwent an additional heat treatment step (900 ${ }^{\circ} \mathrm{C}$ in pure oxygen).

\subsection{Sample Characterization}

The newly produced perovskite was characterized thoroughly: (i) Powder X-ray Diffraction (XRD) measurements were performed to verify phase purity. (ii) Scanning Electron Microscope (SEM) images were recorded to investigate the surface topography of the material. (iii) The specific surface area according to the Brunauer-Emmett-Teller (BET) model [31] was determined to be able to compare the catalytic performance of different samples.

XRD measurements were conducted at room temperature with a PANalytical X'Pert Pro Diffractometer (Malvern Panalytical, Malvern, UK) in Bragg-Brentano geometry, equipped with an $X^{\prime}$ Celerator linear detector (Malvern Panalytical, Malvern, UK) and a mirror to separate the $\mathrm{Cu}-\mathrm{K}_{\alpha 1,2}$ radiation. The HighScore Plus software (Malvern Panalytical, Malvern, UK) [32] together with the PDF-4+2021 Database (ICDD-International Centre for Diffraction Data, Newtown Square, PA, USA) [33] were used for data analysis.

Room temperature SEM images were recorded on a Quanta 250 FEGSEM microscope (FEI Company, Hillsboro, OR, USA) using secondary electrons. All images were recorded using an acceleration voltage of $5 \mathrm{kV}$.

BET areas were calculated from adsorption-desorption isotherms that were in turn determined using an ASAP 2020 PLUS adsorption analyzer (Micromeritics Instrument 
Corporation, Norcross, GA, USA). After a degassing step (for $4 \mathrm{~h}$ under vacuum at $300{ }^{\circ} \mathrm{C}$ ), the samples were cooled to $-196{ }^{\circ} \mathrm{C}$ (liquid $\mathrm{N}_{2}$ ), where full $\mathrm{N}_{2}$ adsorption-desorption isotherms were measured.

\subsection{Catalytic Tests}

The catalytic tests were performed in a tubular flow reactor: 10 to $20 \mathrm{mg}$ of the sample were placed in a quartz glass tube (inner diameter $4 \mathrm{~mm}$ ), mounted in an oven, and exposed to the reaction atmosphere. A total flow of $12 \mathrm{~mL} \mathrm{~min}^{-1}$ was used for all catalytic experiments $\left(4 \mathrm{~mL} \mathrm{~min}{ }^{-1} \mathrm{CO}, 2 \mathrm{~mL} \mathrm{~min}^{-1} \mathrm{O}_{2}\right.$, and $6 \mathrm{~mL} \mathrm{~min}^{-1} \mathrm{Ar}$ as carrier gas, all gases purchased from the Messer Group $\mathrm{GmbH}$, Bad Soden, Germany). Two different temperature programs were used: (i) 150 to $500{ }^{\circ} \mathrm{C}$ (at a rate of $1{ }^{\circ} \mathrm{C} \mathrm{min}-1$ ) for all samples during the heating experiments and (ii) a temperature between 500 and $350{ }^{\circ} \mathrm{C}$ (depending on the sample, shown are curves starting at $400{ }^{\circ} \mathrm{C}$ ) to $50^{\circ} \mathrm{C}$ (at a rate of $-1{ }^{\circ} \mathrm{C} \mathrm{min}-1$ ).

Reaction progress was monitored via continuous sampling (approximately $4 \mathrm{~min}$ intervals) of the gas composition after the reactor using a Micro Gas Chromatograph (Micro-GC, Fusion 3000A, Inficon, Bad Ragaz, Switzerland).

Prior to catalytic testing, a blank measurement (same experimental parameters, but without catalyst) was carried out to check for effects of the reactor setup. The found amount of $\mathrm{CO}_{2}$ was below $0.6 \mathrm{~mol}-\% \mathrm{CO}_{2}$ at $600{ }^{\circ} \mathrm{C}$. Therefore, the contribution of the reactor to the catalytic activity is miniscule enough that no additional corrections were performed.

To achieve comparability between the catalytic results of different samples, specific activities normalized to the sample masses and the BET areas of the respective material were used (for details refer to the Supplementary Materials). This is necessary since commonly used Turn-Over Frequencies (TOFs) require detailed information about active sites. However, due to the dynamic nature of perovskites, these details are not feasibly obtainable: For instance, vacancy concentrations in samples are highly temperature dependent, and the surfaces exposed to the reaction atmospheres in the used powder samples are highly variable as well (in terms of crystallographic orientation, termination, and actual dopant content).

\section{Results}

\subsection{Characterization of Newly Synthesized Perouskite}

XRD measurements after the synthesis of $\mathrm{NdNi}$ (Figure 1) revealed that the final product is not entirely phase-pure: aside from the predominant perovskite phase $\mathrm{Nd}_{0.6} \mathrm{Ca}_{0.4} \mathrm{Fe}_{0.97}$ $\mathrm{Ni}_{0.03} \mathrm{O}_{3-\delta}$, small amounts of an ordered oxygen vacancy structure (Brownmillerite, $\mathrm{Nd}_{2-\mathrm{x}} \mathrm{Ca}_{\mathrm{x}} \mathrm{Fe}_{2-\mathrm{y}} \mathrm{Ni}_{\mathrm{y}} \mathrm{O}_{5}$ ) are also present.

In order to achieve oxygen saturation, a second heating treatment in a pure oxygen atmosphere was performed on a part of the powder; however, the second Brownmillerite phase was present even after this step. The newly synthesized perovskite was still included in the catalytic tests to also investigate the $\mathrm{CO}$ oxidation capabilities of Ni-doped samples (material without the second heating treatment was used for catalytic tests).

SEM images recorded to characterize the sample surface show typical characteristics of preparation by calcination and grinding: varying grain sizes resulting from the grinding process and fused small crystallites making up the overall structures are visible (for the images refer to Section 3.4, where the SEM images of the pristine catalyst are compared to the catalyst after catalytic tests). 


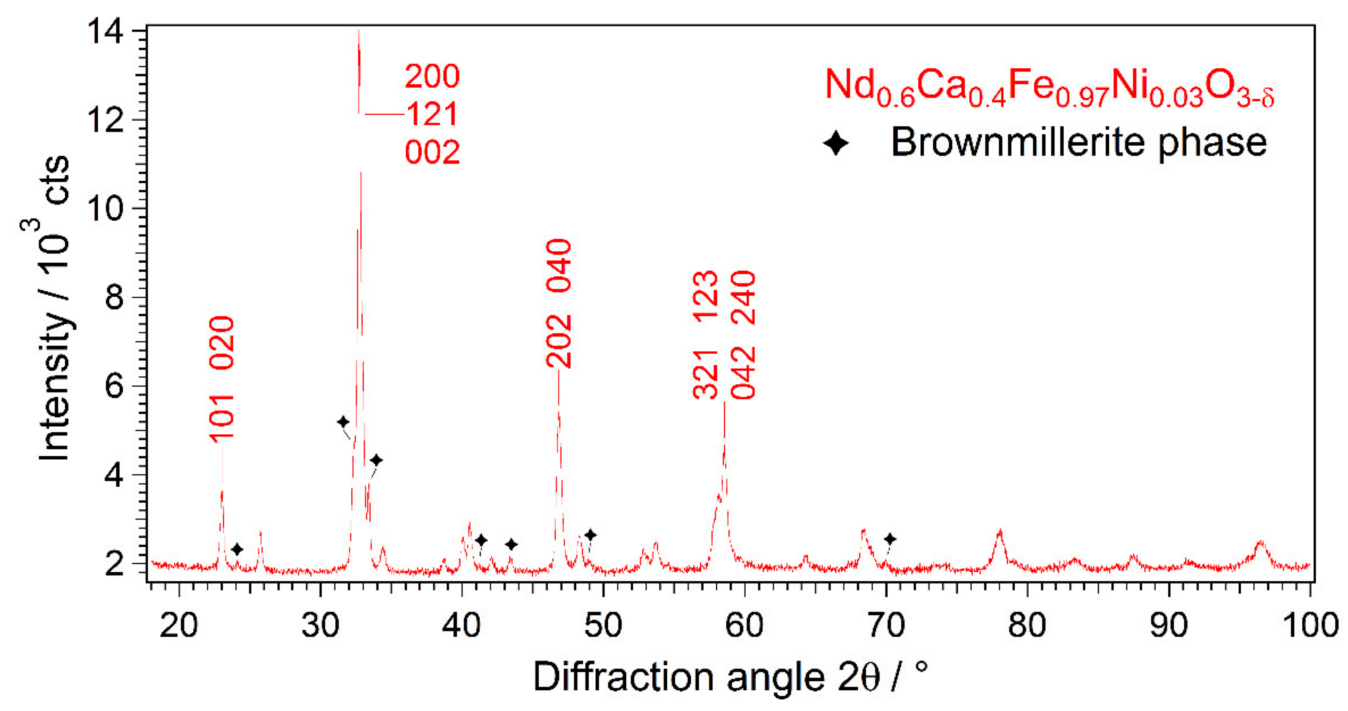

Figure 1. XRD pattern of newly synthesized NdNi. The black stars indicate additional reflexes of an emerging impurity phase-Brownmillerite, $\mathrm{Nd}_{\mathrm{x}} \mathrm{Ca}_{2-\mathrm{x}} \mathrm{Fe}_{2-\mathrm{y}} \mathrm{Ni}_{\mathrm{y}} \mathrm{O}_{5}$ - which exhibits an ordered vacancy structure. All other reflexes correspond to an orthorhombic perovskite phase (only the main reflexes were indexed for clarity-for a more comprehensive reflex assignment refer to [3]).

\subsection{Catalytic Results}

Table 1 summarizes the results of the catalytic tests: listed are the BET areas used to calculate the specific activities (see SI for details) and the specific activities both after heating (at $500{ }^{\circ} \mathrm{C}$ ) and before extinction (i.e., a marked drop of activity) during the cooling ramps.

Table 1. Results of catalytic tests: Specific activities at $500{ }^{\circ} \mathrm{C}$ (heating experiments) and shortly before extinction (cooling experiments). BET areas used to calculate activities are also given.

\begin{tabular}{|c|c|c|c|}
\hline Sample & $\begin{array}{l}\text { BET Area } \\
\left(\mathrm{m}^{2} \cdot \mathrm{g}^{-1}\right)\end{array}$ & $\begin{array}{c}\text { Specific Activity } \\
\text { at } 500^{\circ} \mathrm{C} \\
\left(\times 10^{-5} \mathrm{~mol} \cdot \mathrm{s}^{-1} \cdot \mathrm{m}^{-2}\right)\end{array}$ & $\begin{array}{c}\text { Specific Activity } \\
\text { Before Extinction } \\
\left(\times 10^{-5} \mathrm{~mol} \cdot \mathrm{s}^{-1} \cdot \mathrm{m}^{-2}\right)\end{array}$ \\
\hline La06 & $2.8^{1}$ & 7.2 & 2.6 \\
\hline La09 & $3.8^{1}$ & 6.1 & 3.5 \\
\hline $\mathrm{Nd} 06$ & $1.5^{1}$ & 13.6 & 5.9 \\
\hline Nd09 & $2.2^{1}$ & 8.5 & 3.4 \\
\hline $\mathrm{NdCo}$ & $1.2^{1}$ & 12.7 & 4.6 \\
\hline $\mathrm{NdNi}$ & 2.4 & 7.3 & 3.5 \\
\hline LSF & $5.7^{1}$ & 4.0 & 1.2 \\
\hline
\end{tabular}

${ }^{1}$ BET areas taken from a previous study [29].

The progression of the specific activities during the heating experiments (Figure 2) follows the same pattern for all investigated samples: At lower temperatures an exponential increase (at low levels) is followed by a sharp jump in activity (ignition). After this ignition, the specific activities continue to rise linearly with very similar rates for all catalysts except LSF.

In the case of the four B-site undoped perovskites, clear trends emerge. Both La-based materials exhibit activities below the Nd-based ones. Additionally, there appears to be a positive effect of $\mathrm{Ca}$ on the activity; after ignition, both La06 and Nd06 have higher activities than their counterparts with lower amounts of Ca over the whole temperature range. However, the difference between $\mathrm{La} 06$ and $\mathrm{La} 09$ is less pronounced than for $\mathrm{Nd} 06$ and Nd09. 


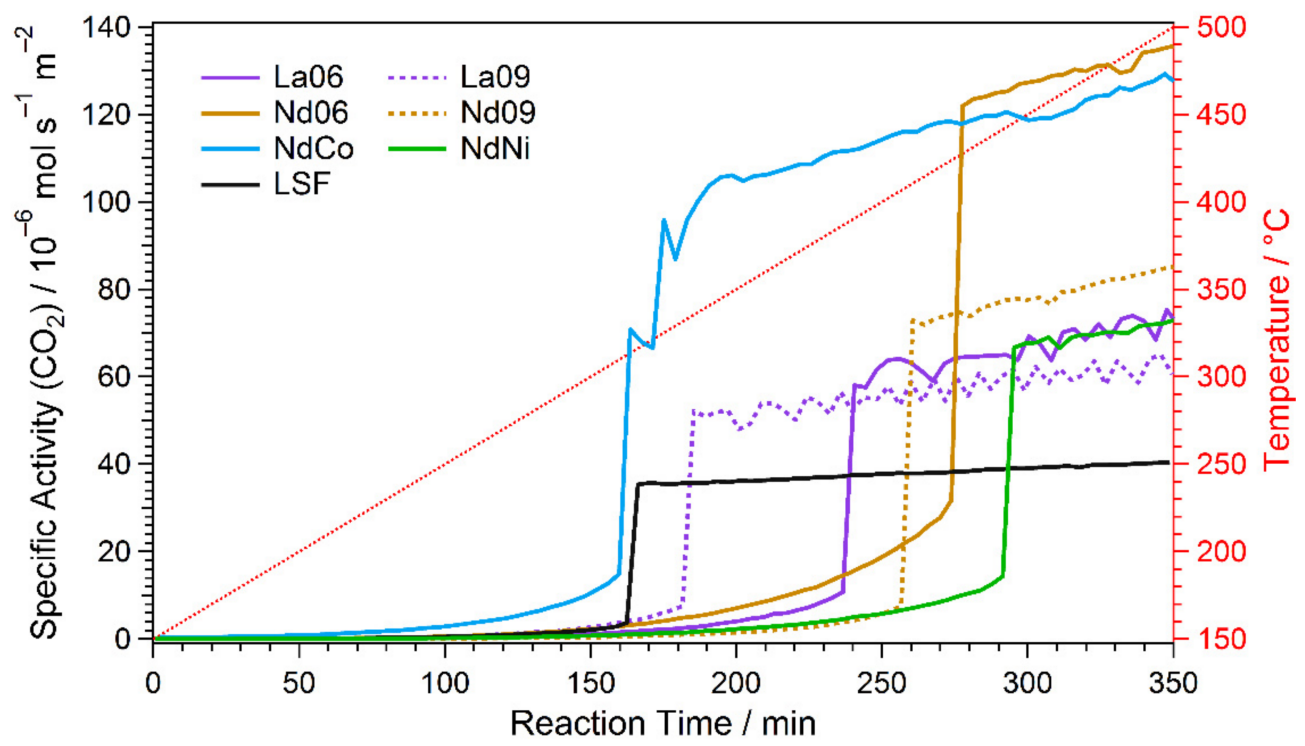

Figure 2. Comparison of $\mathrm{CO}$ oxidation results during heating experiments. The specific activities of the respective perovskites are shown. LSF was added as reference (full black line); the temperature progression during the catalytic test is displayed on the second y-axis. To perform the catalytic tests, a 2:1 mixture of $\mathrm{CO}$ and $\mathrm{O}_{2}$ was used for stoichiometric reasons $\left(4 \mathrm{~mL} \mathrm{~min}^{-1}\right.$ and $2 \mathrm{~mL} \mathrm{~min}^{-1}$, respectively). The temperature was increased from 150 to $500{ }^{\circ} \mathrm{C}$ at a rate of $1^{\circ} \mathrm{C} \mathrm{min}{ }^{-1}$. The highest activities were found for the B-site undoped sample Nd06 and the Co-doped perovskite NdCo. LSF performed worse than all investigated samples.

Moreover, it can be noted that the earlier ignition happens (cf. Section 3.3), the lower the final specific activity will be: La09 displays the earliest ignition of the four but reaches only about $50 \%$ of the maximum specific activity found for $\mathrm{Nd} 06$. The B-site doped samples, $\mathrm{NdCo}$ and $\mathrm{NdNi}$, are the exception: $\mathrm{NdCo}$ is the catalyst that ignites the earliest, but it reaches a maximum activity in the same order of Nd06. In contrast, $\mathrm{NdNi}$ surprisingly exhibits the highest ignition temperature while only displaying a maximum activity comparable to La06.

Co-doping appears to be beneficial, as it lowers the ignition temperature while not impeding the activity of the sample-making $\mathrm{CO}$ oxidation feasible at lower temperatures as well. This is not the case for Ni-doping, which, in fact, seems detrimental to the catalyst performance, as the specific activity is drastically lowered (to about $50 \%$ of the value of $\mathrm{Nd} 06$ ) and ignition is shifted to higher temperatures. However, this might be related to the presence of the additional Brownmillerite phase.

The commercial reference catalyst LSF exhibits the lowest of all found specific activities and ignites around a similar temperature as $\mathrm{NdCo}$, continuing the trend of the undoped perovskites that earlier ignition leads to smaller specific activity.

Aside from the fact that $\mathrm{Nd}$-based samples exhibit higher specific activities than their La-based counterparts, similar trends could not be observed for the specific activities during cooling experiments (summarized in Figure 3).

While the rates of the linear activity increase after ignition during the heating experiments are similar for all catalysts, two different groups of samples with clearly different deactivation rates emerge: The activities of the Nd-based B-site undoped samples Nd06 and $\mathrm{Nd} 09$, the Co-doped perovskite $\mathrm{NdCo}$, and $\mathrm{La06}$ decline at similar rates. This rate is lower in the case of the remaining samples (La09, NdNi, and LSF). Moreover, those samples do not display an extinction event above $50^{\circ} \mathrm{C}$. 


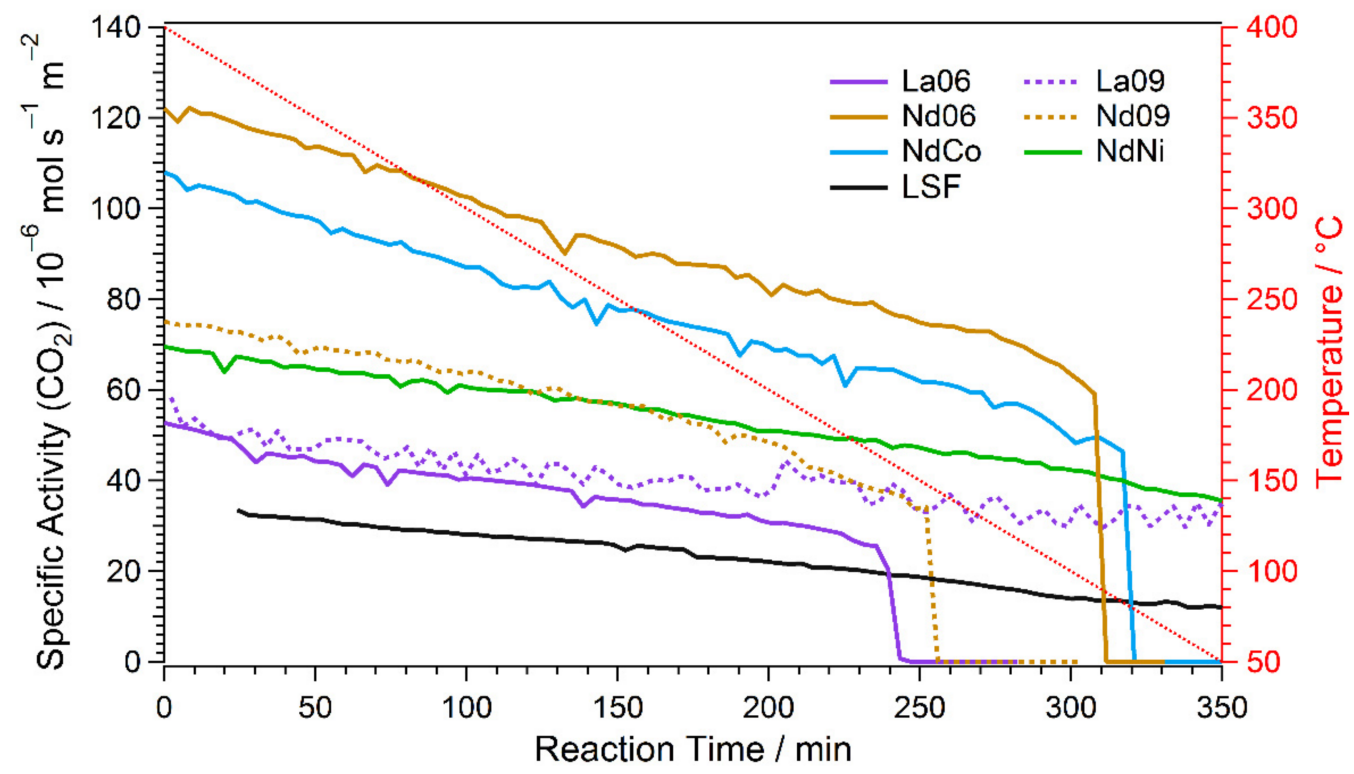

Figure 3. Comparison of $\mathrm{CO}$ oxidation results during cooling experiments. The specific activities of the respective perovskites are shown. LSF was added as reference (full black line); the temperature progression during the catalytic test is displayed on the second y-axis. To perform the catalytic tests, a 2:1 mixture of $\mathrm{CO}$ and $\mathrm{O}_{2}$ was used for stoichiometric reasons $\left(4 \mathrm{~mL} \mathrm{~min}{ }^{-1}\right.$ and $2 \mathrm{~mL} \mathrm{~min}^{-1}$, respectively). The temperature was decreased from 400 to $50{ }^{\circ} \mathrm{C}$ at a rate of $-1{ }^{\circ} \mathrm{C} \mathrm{min}-1$. The highest activities right before extinction were found for the B-site undoped sample $\mathrm{Nd06}$ and the Co-doped perovskite NdCo (similar to the heating experiments). While LSF exhibits the lowest activities over the whole tested temperature range, it does not show extinction above $50{ }^{\circ} \mathrm{C}$. The same is true for La09 and NdNi.

The Nd-based B-site undoped samples exhibit inverted behavior compared to the heating experiments ( $\mathrm{Nd} 06$ displays higher activities over the whole temperature range and deactivates at lower temperatures than Nd09), the same is not true for the La-based analogues: Initially both La06 and La09 start at similar activities; however, the deactivation rate of La06 is larger and extinction occurs at significantly higher temperatures compared to La09.

\subsection{Hysteresis of Specific Activity, Ignition and Extinction}

Figures 4 and 5 show the development of the specific activities during heating and subsequent cooling ramps for $\mathrm{Nd} 06$ and $\mathrm{Nd} 09$, respectively. Both samples show a pronounced hysteresis, which is present for all perovskites tested. During cooling, all samples remain in a state of high specific activity far beyond the ignition temperature; the narrowest hysteresis is that of $\mathrm{La06}\left(226^{\circ} \mathrm{C}\right)$, the largest occurs for $\mathrm{NdNi}\left(>391{ }^{\circ} \mathrm{C}\right.$, an exact value could not be determined as no extinction happened above $50{ }^{\circ} \mathrm{C}$ ).

Insets in Figures 4 and 5 show an additional effect during the heating experiments. The onset of significant oxidation around the ignition temperature leads to the release of additional heat (CO oxidation is exothermic). This, subsequently, causes a spike in the temperature as the PID controller of the heating needs time to compensate for that additional heat. The brief phase of oscillations around the preset temperature arises from initial overcorrections. 


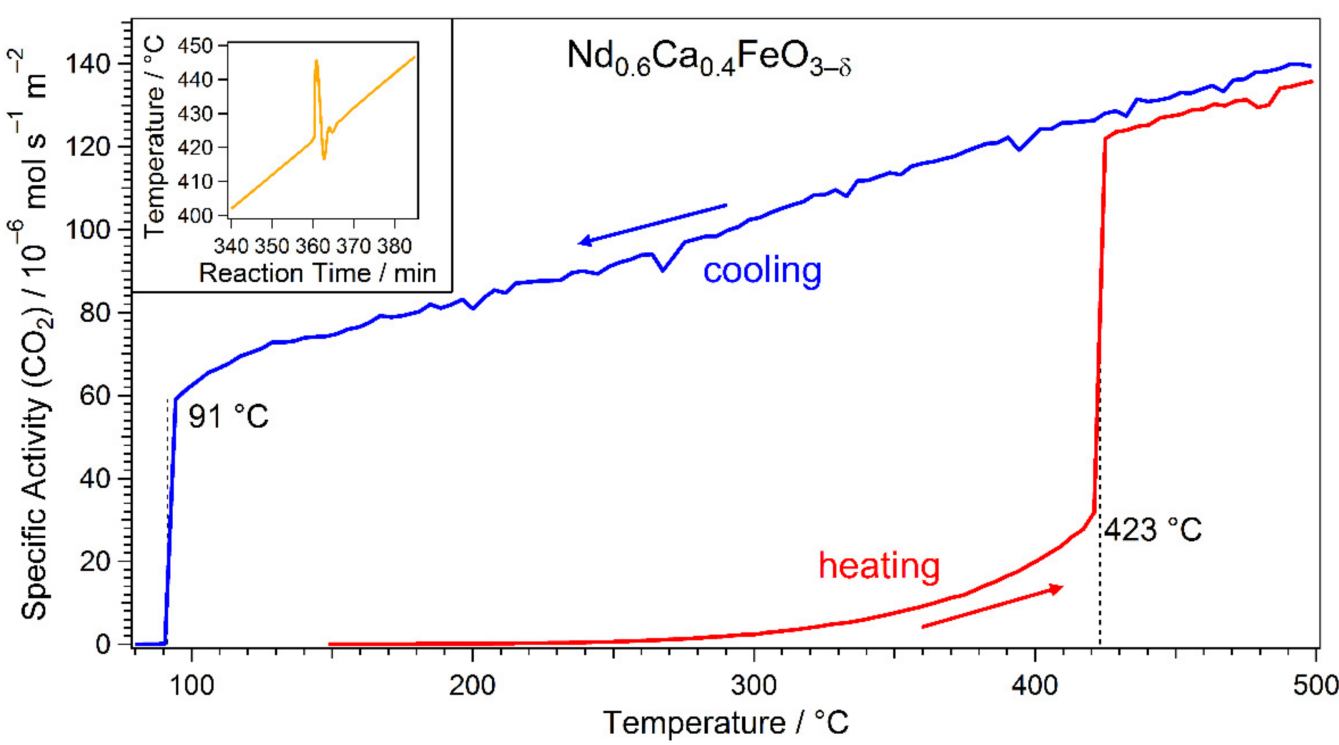

Figure 4. Hysteresis of $\mathrm{Nd}_{0.6} \mathrm{Ca}_{0.4} \mathrm{FeO}_{3-\delta}(\mathrm{Nd} 06)$ : Ignition (onset of significant catalytic activity) upon heating the sample (red curve) happens at $423^{\circ} \mathrm{C}$, while catalytic activity persisted far below that temperature during the cooling of the sample (blue curve). For Nd06, extinction (a significant sudden drop of specific activity) was found to happen at $91^{\circ} \mathrm{C}$. The inset shows an additional thermal effect that could be observed during heating: Due to the exothermic nature of CO oxidation, the temperature spikes around ignition as additional heat is released during the reaction-the peak below the target temperature immediately after this spike arose from the PID controller of the heating overcorrecting. The inverse effect was found around extinction (not shown).

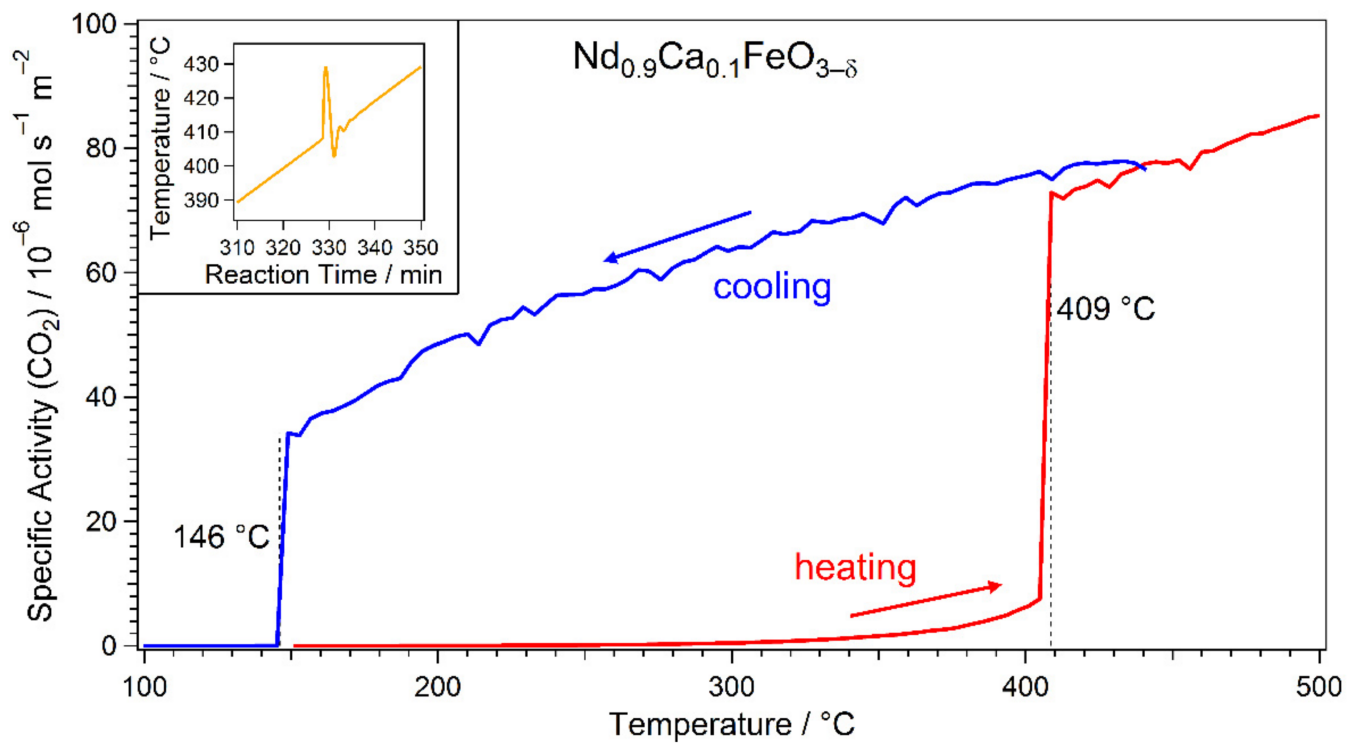

Figure 5. Hysteresis of $\mathrm{Nd}_{0.9} \mathrm{Ca}_{0.1} \mathrm{FeO}_{3-\delta}$ (Nd09): Ignition (onset of significant catalytic activity) upon heating the sample (red curve) happens at $409{ }^{\circ} \mathrm{C}$, while catalytic activity persisted far below that temperature during the cooling of the sample (blue curve). For $\mathrm{Nd06}$, extinction (a significant sudden drop of specific activity) was found to happen at $146{ }^{\circ} \mathrm{C}$. The inset shows an additional thermal effect that could be observed during heating: Due to the exothermic nature of $\mathrm{CO}$ oxidation, the temperature spikes around ignition as additional heat is released during the reaction-the peak below the target temperature immediately after this spike arose from the PID controller of the heating overcorrecting. The inverse effect was found around extinction (not shown). 
The ignition and extinction temperatures for all samples and LSF are summarized in Table 2, as well as specific activities before extinction and after ignition. As mentioned above (see Section 3.2), trends can be derived from the ignition temperatures: Ignition occurs earlier for La-based perovskites La06, La09, and LSF; however, those three samples display lower activities compared to the $\mathrm{Nd}$-based samples except for $\mathrm{NdNi}$.

Table 2. Ignition and extinction temperatures of all samples and LSF. The specific activities before extinction and after ignition are also given.

\begin{tabular}{|c|c|c|c|c|}
\hline Sample & $\begin{array}{c}\text { Ignition } \\
\text { Temperature } \\
\left({ }^{\circ} \mathrm{C}\right)\end{array}$ & $\begin{array}{c}\text { Specific Activity } \\
\text { Before Ignition } \\
\left(\times 10^{-5} \mathrm{~mol} \cdot \mathrm{s}^{-1} \cdot \mathrm{m}^{-2}\right)\end{array}$ & $\begin{array}{l}\text { Specific Activity } \\
\text { After Ignition } \\
\left(\times 10^{-5} \mathrm{~mol} \cdot \mathrm{s}^{-1} \cdot \mathrm{m}^{-2}\right)\end{array}$ & $\begin{array}{c}\text { Extinction } \\
\text { Temperature } \\
\left({ }^{\circ} \mathrm{C}\right)\end{array}$ \\
\hline La06 & 387 & 1.1 & 7.7 & 161 \\
\hline La09 & 334 & 0.8 & 5.2 & $<50$ \\
\hline Nd06 & 423 & 3.2 & 12.2 & 94 \\
\hline Nd09 & 409 & 0.8 & 7.3 & 146 \\
\hline \multirow{2}{*}{$\mathrm{NdCo}^{1}$} & 311 & 1.5 & 7.1 & \multirow{2}{*}{78} \\
\hline & 322 & 6.7 & 9.6 & \\
\hline $\mathrm{NdNi}$ & 441 & 1.4 & 6.7 & $<50$ \\
\hline LSF & 311 & 0.4 & 3.5 & $<50$ \\
\hline
\end{tabular}

1 Two distinct ignitions could be observed for this sample.

Samples with lower amounts of Ca-doping at the A-site (La09 and Nd09) ignite earlier and show lower activities than samples with a higher Ca-content (La06 and Nd06).

Additionally, NdCo exhibits a two-step ignition process. A possible reason for that might be that the processes responsible for that effect happen twice (once for the main constituent $\mathrm{Fe}^{3+}$ and once for the dopant $\mathrm{Co}^{3+}$ ). A similar effect would be expected for NdNi; however, no two-step ignition could be observed. This probably has to do with impurity phase Brownmillerite in this sample.

No clear trends can be formulated for the extinction temperatures found in the cooling experiments. Moreover, three samples (La09, NdNi, and LSF) do not exhibit extinction at all in the investigated temperature range.

\subsection{SEM Images and XRD Diffractograms after CO Oxidation}

SEM images of all samples before and after the catalytic tests were recorded to ascertain whether the catalysts' surface change during $\mathrm{CO}$ oxidation. This is shown exemplarily for NdNi and Nd09 in Figures 6 and 7, respectively (SEM images for all other samples can be found in the Supplementary Materials, Figures S1-S5).

In the case of $\mathrm{NdNi}$, no significant changes to the surface morphology were found; however, for $\mathrm{Nd} 09$, sub-micron sized particles are visible after reaction (Figure $7 \mathrm{~d}$ ). These particles could be identified as $\mathrm{CaCO}_{3}$ via XRD (see Figure 8).

XRD diffractograms of $\mathrm{Nd09}, \mathrm{La06}$, and $\mathrm{NdNi}$ both before and after $\mathrm{CO}$ oxidation are displayed in Figure 8. NdNi showed no significant change after reaction (peak position and width as well as the present phases remained unchanged). Nd09 and La06 exhibit slight changes. In the diffractogram of the former, a small amount of a new phase $\left(\mathrm{CaCO}_{3}\right)$ appears after $\mathrm{CO}$ oxidation. XRD patterns of $\mathrm{Nd06}$ and $\mathrm{NdCo}$ after reaction (not shown) show small amounts of $\mathrm{CaCO}_{3}$ as well. No new phases appear in the case of La06; however, the reflexes are slightly shifted to lower angles after reaction. 

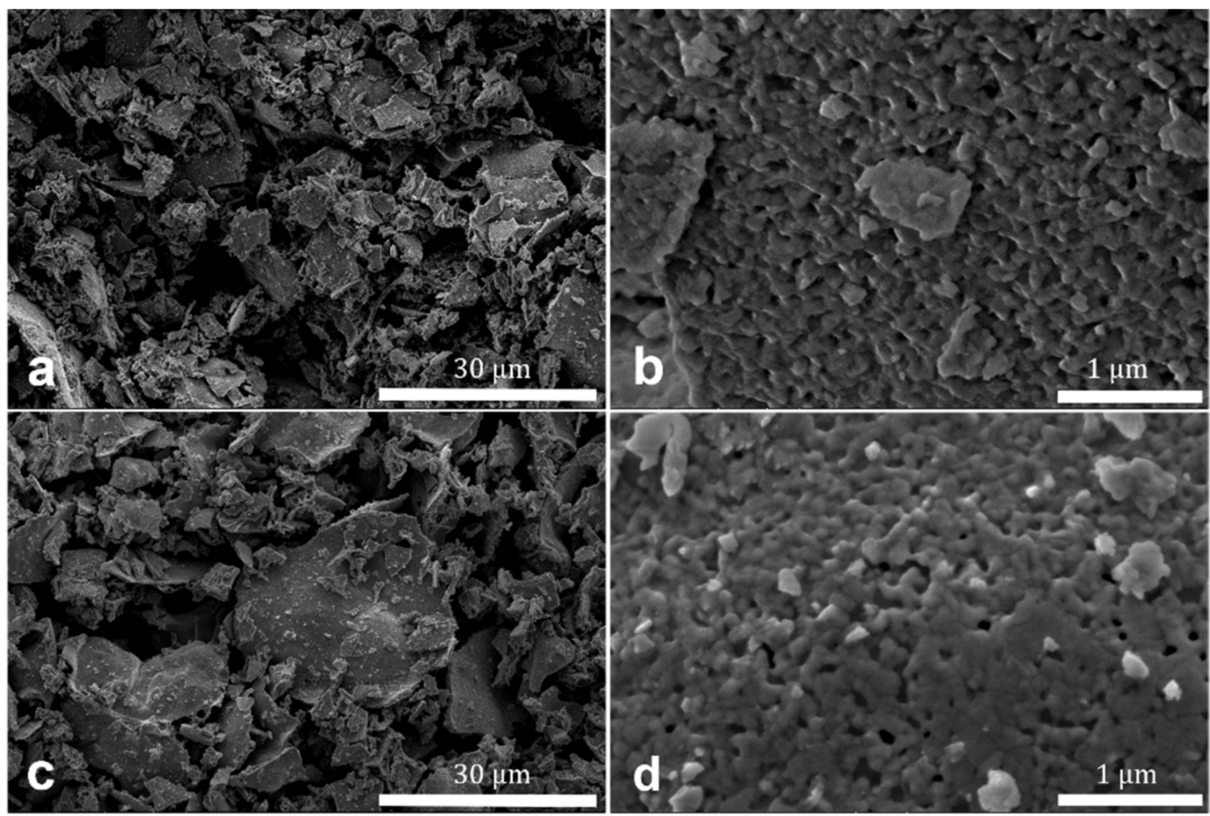

Figure 6. SEM images of NdNi before (a,b) and after a heating ramp (c,d) up to $500{ }^{\circ} \mathrm{C}$. All images were recorded with an acceleration voltage of $5 \mathrm{kV}$. (a) Overview, pristine; (b) selected area, pristine; (c) overview, after reaction; (d) selected area, after reaction. No significant changes to the material's surface are visible.
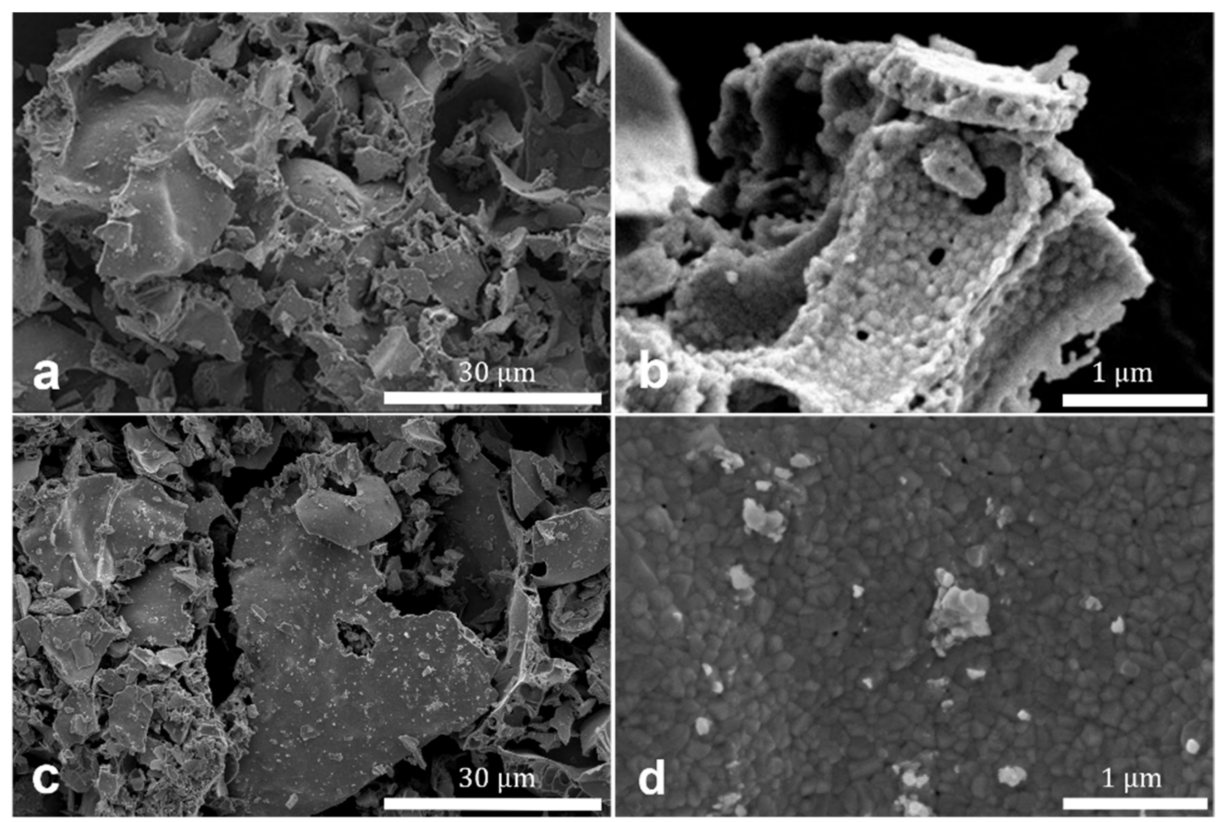

Figure 7. SEM images of Nd09 before (a,b) and after a heating ramp (c,d) up to $500{ }^{\circ} \mathrm{C}$. All images were recorded with an acceleration voltage of $5 \mathrm{kV}$. (a) Overview, pristine; (b) selected area, pristine; (c) overview, after reaction; (d) selected area, after reaction. After reaction, small $\mathrm{CaCO}_{3}$ particles are visible (appearing as brighter spots on the darker perovskite surface). 


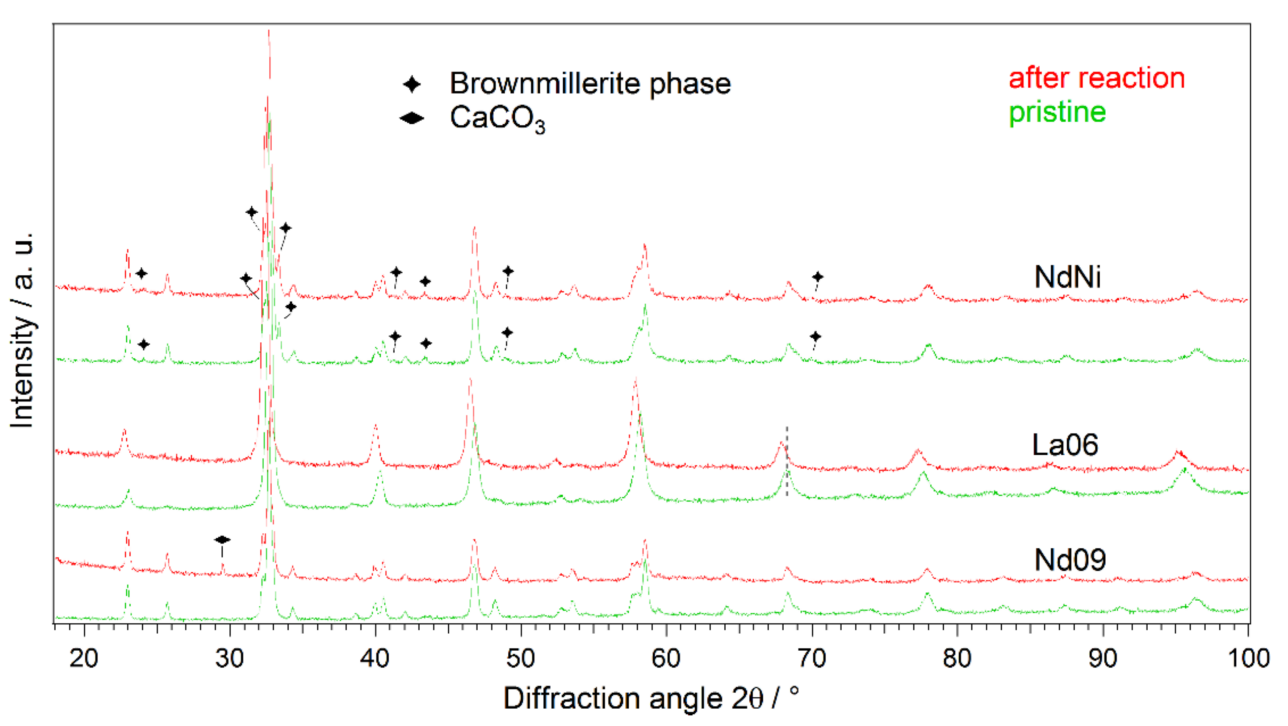

Figure 8. Comparison of XRD patterns of $\mathrm{Nd} 09$, La06, and $\mathrm{NdNi}$ before (green tracks) and after (red tracks) $\mathrm{CO}$ oxidation. Stars denote reflexes of the impurity phase Brownmillerite, the diamond marks a reflex associated with $\mathrm{CaCO}_{3}$. $\mathrm{Nd} 09$ exhibits small amounts of $\mathrm{CaCO}_{3}$ after the reaction, while both La06 and NdNi do not show any new phases after the reaction. However, the reflexes of La06 are shifted to lower angles. No significant changes in the diffractogram of $\mathrm{NdNi}$ were found after $\mathrm{CO}$ oxidation.

\section{Discussion}

All investigated perovskites show a similar progression of the catalytic activity upon heating: at low temperature it increases exponentially, followed by an abrupt jump (ignition). After ignition happened, the activity grows linearly; interestingly, the rate of this growth is similar for all materials studied in this work except LSF. During cooling, an inverted behavior without any exponential decrease was observed. This is because due the hysteresis, deactivation occurs at much lower temperatures than ignition (up to almost $400{ }^{\circ} \mathrm{C}$ later), resulting in the residual activity dropping to 0 immediately.

B-site doping did not lead to increased specific activities. While in the case of $\mathrm{NdCo}$ the activity of the undoped perovskite $\mathrm{Nd} 06$ was reached and ignition was reached much earlier (NdCo is the sample that ignites the earliest), doping with Ni led to a drastically reduced activity and ignition being shifted to higher temperatures ( $\mathrm{NdNi}$ was the last catalyst to ignite). However, it can be assumed that the presence of Brownmillerite is the reason for this decline in catalyst performance, as in earlier studies on reverse water-gas shift reactions, a catalyst with $10 \% \mathrm{Ni}$ and no competing impurity phase present showed improved activity compared to the B-site undoped material [29].

The processes leading to ignition and the catalysis mechanism of $\mathrm{CO}$ oxidation over perovskites are not fully understood. The shape of the activity curves and the presence of $\mathrm{CaCO}_{3}$ in some samples suggests that different mechanisms (schematically depicted in Figure 9) play a role at different reaction conditions:

(i) At lower temperatures, both Langmuir-Hinshelwood- or Eley-Rideal-type mechanisms are plausible as both explain the exponential increase of activity. In the case of the former, catalytic activity would be hindered by full coverage of $\mathrm{CO}$ - as both reactants need to adsorb. Only with increasing temperature and subsequent desorption of $\mathrm{CO}$-freeing adsorption sites for $\mathrm{O}_{2}$ adsorption—can $\mathrm{CO}$ oxidation occur. This dependence on $\mathrm{CO}$ desorption might serve as an explanation for changes of specific activity as different compositions lead to different $\mathrm{CO}$ desorption energies. This mechanism at lower temperatures was proposed by Wang et al. for $\mathrm{La}_{0.4} \mathrm{Sr}_{0.6} \mathrm{CoO}_{3-\delta}$ [34]. Yang et al. investigated a low-temperature Langmuir-Hinshelwood mechanism promoted by oxygen vacancies [35]. An Eley-Rideal mechanism in the presence of $\mathrm{Fe}^{3+}$ ions 
was postulated for $\mathrm{Fe}_{2} \mathrm{O}_{3}$ by Waglöhner et al. [36]. Depending on surface termination and crystallographic direction of facets exposed to the reaction atmosphere, such ions are present in all investigated samples.

(ii) Around ignition, a change of mechanisms is likely: Wang et al. suggest a Mars-vanKrevelen $(\mathrm{MvK})$ mechanism for $\mathrm{La}_{0.4} \mathrm{Sr}_{0.6} \mathrm{CoO}_{3-\delta}$ at high temperatures [34] and Liu et al. put forward either a conventional or a carbonate-mediated MvK mechanism for $\mathrm{CO}$ oxidation over Co-doped ceria catalysts [37]. This aligns with the presence of $\mathrm{CaCO}_{3}$ in $\mathrm{Nd06}$ and $\mathrm{Nd} 09$. Moreover, oxygen vacancies play a crucial role in $\mathrm{MvK}$ mechanisms and have also be found to be important for $\mathrm{CO}$ oxidation using Ce-doped $\mathrm{LaCoO}_{3}$ catalysts [25]. Increasing $\mathrm{Ca}^{2+}$ contents lead to a higher number of vacancies in $\mathrm{LaFeO}_{3}$ - and $\mathrm{NdFeO}_{3}$-based perovskites, which in turn lead to easier $\mathrm{O}_{2}$ adsorption. That can explain the generally higher catalytic activities of the B-site undoped samples with $40 \%$ Ca content [28].

(iii) The linear increase of the catalytic activity after ignition might be related to diffusion limitation.

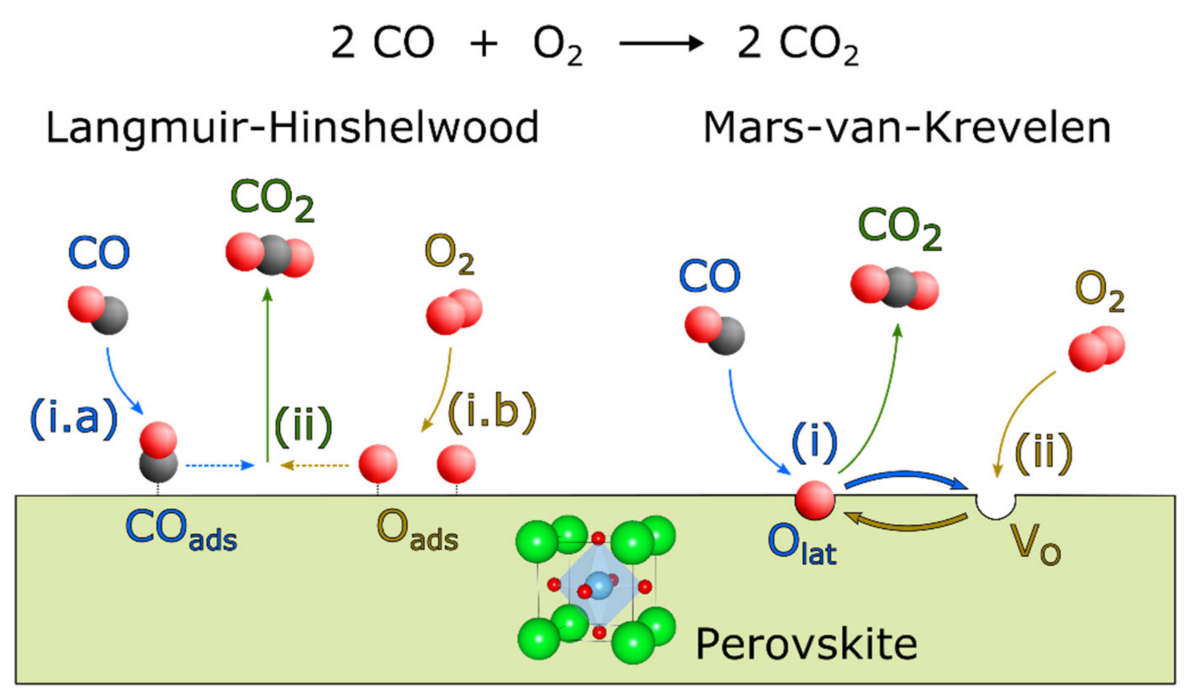

Figure 9. Schematic representation of $\mathrm{CO}$ oxidation on a perovskite surface (ideal cubic unit cell shown in the middle). During a Langmuir-Hinshelwood mechanism (left) both reactants adsorb (i.a and i.b, $\mathrm{CO}_{\mathrm{ads}}$ and $\mathrm{O}_{\mathrm{ads}}$, respectively), diffuse along the surface (ii), and form $\mathrm{CO}_{2}$, which desorbs. The Mars-van-Krevelen (MvK, right) mechanism proceeds via two steps: (i) CO adsorbs first, reacts with lattice oxygen $\left(\mathrm{O}_{\text {lat }}\right)$, and desorbs as $\mathrm{CO}_{2}$ leaving an oxygen vacancy $\left(\mathrm{V}_{\mathrm{O}}\right)$ behind. (ii) An oxygen molecule from the gas atmosphere adsorbs, splits, and re-fills the vacancy.

Moreover, the two-step ignition of NdCo suggest involvement of the B-site species. The B-site undoped species display a single step during ignition (due to only one species$\mathrm{Fe}^{3+}$-making up the B-site); in the case of $\mathrm{NdCo}$ on the other hand, $\mathrm{Fe}^{3+}$ and $\mathrm{Co}^{3+}$ species $^{3}$ compose the B-sublattice. Differences of CO desorption energies between Fe- and Co-sites might cause the two steps.

The results presented in this work demonstrate the flexibility of perovskites: changes in the A-site composition or the introduction of B-site dopants influence the performance of the catalyst with respect to $\mathrm{CO}$ oxidation, thus facilitating a possible pathway to catalyst design. Relatively simple changes to the composition of the catalyst-such as changing the A-site cation $\left(\mathrm{La}^{3+}\right.$ vs. $\left.\mathrm{Nd}^{3+}\right)$ and/or increasing the content of A-site dopant $(10 \%$ or $40 \% \mathrm{Ca}$ - - greatly change the resulting activity and ignition temperature of the catalyst. Pursuing this design approach was the main motivation of the present study.

Supplementary Materials: The following are available online at https:/ /www.mdpi.com/article/10 .3390/fuels3010003/s1, Figure S1: SEM images of La06, Figure S2: SEM images of La09, Figure S3: SEM images of Nd06, Figure S4: SEM images of NdCo, Figure S5: SEM images of LSF. 


\begin{abstract}
Author Contributions: Conceptualization, C.R.; methodology, C.R., F.S., L.L. and R.B.; validation, F.S., L.L. and T.R.; formal analysis, L.L. and T.R.; investigation, R.B. and L.L.; resources, L.L. and R.B.; data curation, L.L. and R.B.; writing-original draft preparation, R.B. and T.R.; writing-review and editing, C.R., F.S., L.L. and T.R.; visualization, F.S., L.L. and C.R.; supervision, C.R.; project administration, C.R.; funding acquisition, C.R. All authors have read and agreed to the published version of the manuscript.
\end{abstract}

Funding: This research was funded by the European Research Council (ERC) under the European Union's Horizon 2020 research and innovation programme, grant agreement no. 755744/ERCStarting Grant TUCAS.

Data Availability Statement: The data presented in this study are available on request from the corresponding author.

Acknowledgments: The X-ray measurements were carried out within the X-ray Center of TU Wien. The SEM images were obtained at the university service center USTEM of TU Wien.

Conflicts of Interest: The authors declare no conflict of interest.

\title{
References
}

1. Geller, S. Crystallographic studies of perovskite-like compounds. 5. Relative ionic sizes. Acta Crystallogr. 1957, 10, 248-251. [CrossRef]

2. $\quad$ Lindenthal, L.; Rameshan, R.; Summerer, H.; Ruh, T.; Popovic, J.; Nenning, A.; Löffler, S.; Opitz, A.K.; Blaha, P.; Rameshan, C. Modifying the Surface Structure of Perovskite-Based Catalysts by Nanoparticle Exsolution. Catalysts 2020, 10, 268. [CrossRef]

3. Lindenthal, L.; Ruh, T.; Rameshan, R.; Summerer, H.; Nenning, A.; Herzig, C.; Löffler, S.; Limbeck, A.; Opitz, A.K.; Blaha, P.; et al Ca-doped rare earth perovskite materials for tailored exsolution of metal nanoparticles. Acta Crystallogr. Sect. B Struct. Sci. Cryst. Eng. Mater. 2020, 76, 1055-1070. [CrossRef]

4. Hwang, J.; Rao, R.R.; Giordano, L.; Katayama, Y.; Yu, Y.; Shao-Horn, Y. Perovskites in catalysis and electrocatalysis. Science 2017, 358, 751-756. [CrossRef]

5. Nishihata, Y.; Mizuki, J.; Akao, T.; Tanaka, H.; Uenishi, M.; Kimura, M.; Okamoto, T.; Hamada, N. Self-regeneration of a Pd-perovskite catalyst for automotive emissions control. Nature 2002, 418, 164-167. [CrossRef]

6. Shin, T.H.; Myung, J.H.; Verbraeken, M.; Kim, G.; Irvine, J.T.S. Oxygen deficient layered double perovskite as an active cathode for $\mathrm{CO}_{2}$ electrolysis using a solid oxide conductor. Faraday Discuss. 2015, 182, 227-239. [CrossRef]

7. Stöger, B.; Hieckel, M.; Mittendorfer, F.; Wang, Z.M.; Fobes, D.; Peng, J.; Mao, Z.Q.; Schmid, M.; Redinger, J.; Diebold, U. High Chemical Activity of a Perovskite Surface: Reaction of $\mathrm{CO}$ with $\mathrm{Sr}_{3} \mathrm{Ru}_{2} \mathrm{O}_{7}$. Phys. Rev. Lett. 2014, 113, 116101. [CrossRef]

8. Katz, M.B.; Zhang, S.Y.; Duan, Y.W.; Wang, H.J.; Fang, M.H.; Zhang, K.; Li, B.H.; Graham, G.W.; Pan, X.Q. Reversible precipitation/dissolution of precious-metal clusters in perovskite-based catalyst materials: Bulk versus surface re-dispersion. J. Catal. 2012, 293, 145-148. [CrossRef]

9. Thalinger, R.; Opitz, A.K.; Kogler, S.; Heggen, M.; Stroppa, D.; Schmidmair, D.; Tappert, R.; Fleig, J.; Klotzer, B.; Penner, S. Water-Gas Shift and Methane Reactivity on Reducible Perovskite-Type Oxides. J. Phys. Chem. C 2015, 119, 11739-11753. [CrossRef]

10. Mueller, D.N.; Machala, M.L.; Bluhm, H.; Chueh, W.C. Redox activity of surface oxygen anions in oxygen-deficient perovskite oxides during electrochemical reactions. Nat. Commun. 2015, 6, 6097. [CrossRef]

11. Bedel, L.; Roger, A.C.; Estournes, C.; Kiennemann, A. Co-0 from partial reduction of $\mathrm{La}(\mathrm{Co}, \mathrm{Fe}) \mathrm{O}_{3}$ perovskites for Fischer-Tropsch synthesis. Catal. Today 2003, 85, 207-218. [CrossRef]

12. Bedel, L.; Roger, A.C.; Rehspringer, J.L.; Zimmermann, Y.; Kiennemann, A. $\mathrm{La}_{1-\mathrm{y}} \mathrm{Co}_{0.4} \mathrm{Fe}_{0.6} \mathrm{O}_{3-\delta}$ perovskite oxides as catalysts for Fischer-Tropsch synthesis. J. Catal. 2005, 235, 279-294. [CrossRef]

13. Escalona, N.; Fuentealba, S.; Pecchi, G. Fischer-Tropsch synthesis over $\mathrm{LaFe}_{1-\mathrm{x}} \mathrm{Co}_{\mathrm{x}} \mathrm{O}_{3}$ perovskites from a simulated biosyngas feed. Appl. Catal. A 2010, 381, 253-260. [CrossRef]

14. Ao, M.; Pham, G.H.; Sage, V.; Pareek, V. Selectivity enhancement for higher alcohol product in Fischer-Tropsch synthesis over nickel-substituted $\mathrm{La}_{0.9} \mathrm{Sr}_{0.1} \mathrm{CoO}_{3}$ perovskite catalysts. Fuel 2017, 206, 390-400. [CrossRef]

15. Zhan, H.J.; Li, F.; Gao, P.; Zhao, N.; Xiao, F.K.; Wei, W.; Zhong, L.S.; Sun, Y.H. Methanol synthesis from $\mathrm{CO}_{2}$ hydrogenation over $\mathrm{La}-\mathrm{M}-\mathrm{Cu}-\mathrm{Zn}-\mathrm{O}(\mathrm{M}=\mathrm{Y}, \mathrm{Ce}, \mathrm{Mg}$, Zr) catalysts derived from perovskite-type precursors. J. Power Source 2014, 251, 113-121. [CrossRef]

16. Tien-Thao, N.; Alamdari, H.; Zahedi-Niaki, M.H.; Kaliaguine, S. $\mathrm{LaCo}_{1-\mathrm{x}} \mathrm{Cu}_{\mathrm{x}} \mathrm{O}_{3-\delta}$ perovskite catalysts for higher alcohol synthesis. Appl. Catal. A 2006, 311, 204-212. [CrossRef]

17. Huš, M.; Kopač, D.; Likozař, B. Catalytic Hydrogenation of Carbon Dioxide to Methanol: Synergistic Effect of Bifunctional $\mathrm{Cu}$ /Perovskite Catalysts. ACS Catal. 2019, 9, 105-116. [CrossRef]

18. Freund, H.J.; Meijer, G.; Scheffler, M.; Schlögl, R.; Wolf, M. CO Oxidation as a Prototypical Reaction for Heterogeneous Processes. Angew. Chem. Int. Ed. 2011, 50, 10064-10094. [CrossRef]

19. Libby, W.F. Promising catalyst for auto exhaust. Science 1971, 171, 499. [CrossRef] 
20. Voorhoev, R.J.; Remeika, J.P.; Matthias, B.T.; Freeland, P.E. Rare-earth oxides of manganese and cobalt rival platinum for treatment of carbon-monoxide in auto exhaust. Science 1972, 177, 353. [CrossRef]

21. Nitadori, T.; Misono, M. Catalytic properties of $\mathrm{La}_{1-x} \mathrm{~A}^{\prime}{ }_{\mathrm{x}} \mathrm{FeO}_{3}\left(\mathrm{~A}^{\prime}=\mathrm{Sr}, \mathrm{Ce}\right)$ and $\mathrm{La}_{1-x} \mathrm{Ce}_{\mathrm{x}} \mathrm{CoO}_{3}$. J. Catal. 1985, 93, 459-466. [CrossRef]

22. Nitadori, T.; Ichiki, T.; Misono, M. Catalytic properties of perovskite-type mixed oxides $\left(\mathrm{ABO}_{3}\right)$ consisting of rare-earth and $3 \mathrm{~d}$ transition-metals-The roles of the A-site and B-site ions. Bull. Chem. Soc. Jpn. 1988, 61, 621-626. [CrossRef]

23. Song, K.S.; Kang, S.K.; Kim, S.D. Preparation and characterization of Ag/ $\mathrm{MnO}_{\mathbf{x}} /$ perovskite catalysts for CO oxidation. Catal. Lett. 1997, 49, 65-68. [CrossRef]

24. Singh, U.G.; Li, J.; Bennett, J.W.; Rappe, A.M.; Seshadri, R.; Scott, S.L. A Pd-doped perovskite catalyst, $\mathrm{BaCe}_{1-\mathrm{x}} \mathrm{Pd}_{\mathrm{x}} \mathrm{O}_{3-\delta}$, for CO oxidation. J. Catal. 2007, 249, 349-358. [CrossRef]

25. Magalhaes, R.; Toniolo, F.S.; Da Silva, V.T.; Schmal, M. Selective CO oxidation reaction (SELOX) over cerium-doped LaCoO 3 perovskite catalysts. Appl. Catal. A 2010, 388, 216-224. [CrossRef]

26. Yan, X.K.; Huang, Q.; Li, B.; Xu, X.L.; Chen, Y.W.; Zhu, S.M.; Shen, S.B. Catalytic performance of $\mathrm{LaCo}_{0.5} \mathrm{M}_{0.5} \mathrm{O}_{3}(\mathrm{M}=\mathrm{Mn}, \mathrm{Cr}$, $\mathrm{Fe}, \mathrm{Ni}, \mathrm{Cu}$ ) perovskite-type oxides and $\mathrm{LaCo}_{0.5} \mathrm{Mn}_{0.5} \mathrm{O}_{3}$ supported on cordierite for $\mathrm{CO}$ oxidation. J. Ind. Eng. Chem. 2013, 19, 561-565. [CrossRef]

27. Huang, K.K.; Chu, X.F.; Yuan, L.; Feng, W.C.; Wu, X.F.; Wang, X.Y.; Feng, S.H. Engineering the surface of perovskite $\mathrm{La}_{0.5} \mathrm{Sr}_{0.5} \mathrm{MnO}_{3}$ for catalytic activity of CO oxidation. Chem. Commun. 2014, 50, 9200-9203. [CrossRef]

28. Popovic, J.; Lindenthal, L.; Rameshan, R.; Ruh, T.; Nenning, A.; Löffler, S.; Opitz, A.K.; Rameshan, C. High Temperature Water Gas Shift Reactivity of Novel Perovskite Catalysts. Catalysts 2020, 10, 582. [CrossRef]

29. Lindenthal, L.; Popovic, J.; Rameshan, R.; Huber, J.; Schrenk, F.; Ruh, T.; Nenning, A.; Löffler, S.; Opitz, A.K.; Rameshan, C. Novel perovskite catalysts for $\mathrm{CO}_{2}$ utilization-Exsolution enhanced reverse water-gas shift activity. Appl. Catal. B 2021, $292,120183$. [CrossRef]

30. Pechini, M.P. Method of Preparing Lead and Alkaline Earth Titanates and Niobates and Coating Method Using the Same to Form a Capacitor. U.S. Patent 3,330,697, 11 July 1967.

31. Brunauer, S.; Emmett, P.H.; Teller, E. Adsorption of gases in multimolecular layers. J. Am. Chem. Soc. 1938, 60, 309-319. [CrossRef]

32. Degen, T.; Sadki, M.; Bron, E.; Konig, U.; Nenert, G. The HighScore suite. Powder Diffr. 2014, 29, S13-S18. [CrossRef]

33. ICDD. PDF-4+ 2021; International Centre for Diffraction Data: Newtown Square, PA, USA, 2020.

34. Wang, X.Y.; Huang, K.K.; Yuan, L.; Xi, S.B.; Yan, W.S.; Geng, Z.B.; Cong, Y.G.; Sun, Y.; Tan, H.; Wu, X.F.; et al. Activation of Surface Oxygen Sites in a Cobalt-Based Perovskite Model Catalyst for CO Oxidation. J. Phys. Chem. Lett. 2018, 9, 4146-4154. [CrossRef] [PubMed]

35. Yang, J.; Hu, S.Y.; Fang, Y.R.; Hoang, S.; Li, L.; Yang, W.W.; Liang, Z.F.; Wu, J.; Hu, J.P.; Xiao, W.; et al. Oxygen Vacancy Promoted $\mathrm{O}_{2}$ Activation over Perovskite Oxide for Low-Temperature CO Oxidation. ACS Catal. 2019, 9, 9751-9763. [CrossRef]

36. Wagloehner, S.; Reichert, D.; Leon-Sorzano, D.; Balle, P.; Geiger, B.; Kureti, S. Kinetic modeling of the oxidation of $\mathrm{CO}$ on $\mathrm{Fe}_{2} \mathrm{O}_{3}$ catalyst in excess of $\mathrm{O}_{2}$. J. Catal. 2008, 260, 305-314. [CrossRef]

37. Liu, B.; Li, W.P.; Song, W.Y.; Liu, J. Carbonate-mediated Mars-van Krevelen mechanism for CO oxidation on cobalt-doped ceria catalysts: Facet-dependence and coordination-dependence. Phys. Chem. Chem. Phys. 2018, 20, 16045-16059. [CrossRef] [PubMed] 